\title{
RETRACTED ARTICLE: \\ In Search of the Guilty: Analysis of the Migration of Encephalitogenic T-Cells at the Preclinical Stage of Development of Adoptive Experimental Autoimmune Encephalomyelitis (EAE) after Their Intravenous or Intraperitoneal Administration
}

\author{
M. A. Nosov, ${ }^{1,2}$ A. Flügel, ${ }^{3}$ and E. A. Korneva
}

This article has been retracted due to incorrect attribution of authors.

\footnotetext{
${ }^{1}$ Institute of Experimental Medicine, Russian Academy of

Medical Sciences, 12 Academician Pavlov Street, 197376

St. Petersburg; e-mail: mikhail.nosov@nuigalway.ie.

${ }^{2}$ Regenerative Medicine Institute, Galway, Ireland.

${ }^{3}$ Institute for Multiple Sclerosis Research, Göttingen, Germany.
} 